\title{
Pros

\section{DOCUDRAMA Y AUTOFICCIÓN EN EL TEATRO ARGENTINO DE LA POSDICTADURA}

MAURICIO TOSSI

CONICET-Universidad Nacional de Río Negro

Con el regreso a la democracia en el año 1983, el teatro en la República Argentina inicia nuevos y diversos procesos de subjetivación de las identidades culturales, esto último, por ejemplo, al abordar las prácticas ominosas del terrorismo de Estado desde divergentes lineamientos poéticos. De este modo, ciertas producciones teatrales de la fase posdictatorial pueden comprenderse -al igual que otras creaciones literarias, visuales y cinematográficas del mismo períodocomo activos "vehículos de la memoria" histórica, según las definiciones de la socióloga Elizabeth Jelin (2002).

Estos posicionamientos artístico-intelectuales actualizan los debates sobre cómo evocar en términos poéticos las contradicciones culturales y los fenómenos siniestros de la última dictadura cívico-militar, como así también plantean la necesidad de una revisión estética de los recursos escénicos utilizados.

Por consiguiente, en este ensayo nos proponemos indagar en los mecanismos de representación de la memoria histórica a través de un estudio dramatológico, puntualmente, al reconocer un cambio de estrategia poética en los referentes documentales utilizados en ciertas producciones teatrales argentinas y su tendencia hacia prácticas escénicas autoficcionales.

LA FORMULACIÓN DEL PROBLEMA: UN INTENTO DE DELIMITACIÓN

Con el fin de acotar el análisis a fenómenos específicos, inscribiremos nuestras reflexiones sobre el teatro en el "reordenamiento ideológico y con- 
ceptual" que Beatriz Sarlo ha denominado "giro subjetivo". Respecto de este concepto, la mencionada autora dice:

\begin{abstract}
Este reordenamiento ideológico y conceptual de la sociedad del pasado y sus personajes, que se concentra sobre los derechos y la verdad de la subjetividad, sostiene gran parte de la empresa reconstructiva de las décadas del sesenta y setenta. Coincide con una renovación análoga en la sociología de la cultura y los estudios culturales, donde la identidad de los sujetos ha vuelto a tomar el lugar que, en los años sesenta, fue ocupado por las estructuras. Se ha restaurado la razón del sujeto, que fue, hace décadas, mera "ideología" o "falsa conciencia", es decir, discurso que encubría ese depósito oscuro de impulsos o mandatos que el sujeto necesariamente ignoraba. En consecuencia, la historia oral y el testimonio han devuelto la confianza a esa primera persona que narra su vida (privada, pública, afectiva, política), para conservar el recuerdo o para reparar una identidad lastimada. (Sarlo, 2005: 22)
\end{abstract}

Por consiguiente, nos preguntamos: ¿cómo se evidencia este "giro subjetivo" en el teatro argentino de la posdictadura? ¿Es posible reconocer una lógica escénica en el marco de este reordenamiento ideológico y conceptual del pasado, por ejemplo, evidenciado en el pasaje de un teatro con confianza en la "verdad estructural" hacia un teatro con confianza en el "yo deconstruido"?

Una manera de observar el desplazamiento de lo objetivo/estructural hacia lo subjetivo/deconstruido en el teatro argentino de la posdictadura es, por ejemplo, tomar como eje problemático sus fuentes referenciales y su correlativo ejercicio contratextual, esto implica, entre otras posibilidades, abordar la relación poética que se establece a partir del "documento histórico" como prueba de verdad y como base para la elaboración de discursos sobre la memoria.

Desde esta perspectiva, proponemos el siguiente ejercicio reflexivo: examinar los procedimientos dramatúrgicos utilizados en determinados montajes teatrales regionales que, fundamentalmente, han usado y resemantizado "documentos históricos" como fuentes para sus estructuras de ficción, esto último según tres formas diferenciadas, a saber:

a) el docudrama o teatro documental ${ }^{1}$ como una forma poética de amplia tradición latinoamericana que, entre otras características, predica o denuncia una tesis estructural y objetiva sobre lo histórico-contemporáneo, a través de núcleos referenciales fácilmente reconocibles por el lector/ espectador;

b) una variante del docudrama que, si bien organiza la construcción de su relato a partir de documentos reales y comprobados, busca ampliar el grado de poíesis (Dubatti, 2009) de dichos documentos; así, funda un pacto ambiguo y convierte al referente histórico no solo en una verdad fáctica sino también en una "verdad poética", con el fin de provocar un "efecto de sentido" crítico sobre el pasado y el presente;

c) el pasaje concreto de lo estructural/objetivo de una tesis documental hacia lo subjetivo/deconstruido en su forma de -podríamos llamar-

\footnotetext{
${ }^{1}$ A lo largo del ensayo, utilizaremos de manera indistinta ambas denominaciones.
} 
"teatro autoficcional". En esta modalidad, el documento histórico presentado en escena es el cuerpo vivo del actor, en tanto opera como un objeto de conocimiento y no como un referente extratextual o extraescénico.

A continuación, describiremos algunos procedimientos dramatúrgicos de las tres formas mediante casos de estudio estratégicos².

1. La tesis estructural/objetiva en el docudrama: el CASO de la obra El maRUCHITO... DE JUAN RAÚl RITHNER

El docudrama se desarrolló en los campos culturales de América Latina desde finales de la década de 1960, como una variante del teatro realistahistórico que permitía a los agentes artísticos desarrollar ideologemas sociales específicos según las premisas políticas de aquellos años. En ese marco, sin lugar a dudas, el ensayo teórico "Notas sobre el teatro documental" de Peter Weiss operó como un texto "faro" para los intelectuales comprometidos de la escena latinoamericanista. Así, las características de esta forma escénica propuesta por Weiss en sus famosas catorce tesis se plasmaron de manera eficaz en los grupos Teatro La Candelaria de Bogotá, Yuyachkani de Lima, Libre Teatro Libre de Córdoba (Argentina), o en la dramaturgia del mexicano Vicente Leñero, entre otros muchos casos. En aquel ensayo modélico de Weiss (1976: 99-110), se definía el docudrama con las siguientes características:

-Es un teatro de información con apelaciones reflexivas, expresado en múltiples huellas históricas (actas, cartas, cuadros estadísticos, entrevistas, fotografías, etc.) que se exponen sin variación de contenido y se seleccionan con el fin de analizar un tema específico desde una perspectiva materialista.

-El teatro documental tiene por función develar la "falsa conciencia" sostenida en los discursos dominantes, ya sean, periodísticos, económicos, religiosos o histórico-oficiales; es decir, retomando las ideas de Sarlo antes expuestas, esta forma escénica tiene por meta desnudar los ideologemas y las tácticas de los sectores hegemónicos, al revelar sus lógicas de poder estructural.

-El docudrama renuncia a la función inventiva para dar lugar a la verdad histórica de los hechos empíricamente comprobables, pero no renuncia a experimentar en la potencialidad artística que emerge de lo "real/documentado", pues su eficacia política se consolida en la fuerza estética de la obra (Weiss, 1976: 103). Ante la fragmentación de una realidad compleja y dispersa, esta modalidad teatral asume como técnica el montaje de dichos fragmentos, pero a través de un tajante ejercicio crítico y partidista, al exponer las pruebas a dictamen del espectador, explicar las causas y consecuencias del fenómeno $y$, finalmente, al proyectar una tesis sobre el

\footnotetext{
2 El criterio de selección de los casos a analizar responde a una perspectiva regional, vale decir, intentamos organizar este ejercicio reflexivo a partir de las experiencias teatrales de zonas culturales y campos intelectuales diversos de la República Argentina, puntualmente, las regiones Noroeste, Patagonia y Ciudad Autónoma de Buenos Aires.
} 
tema, la que implica una evidente toma de posición frente a la conflictividad social abordada.

Esta forma escénica, caracterizada por nosotros como estructural/objetiva, tiene a finales de los años 1980 una fase de crisis estética, ideológica y comunicacional. Así, los agentes teatrales más representativos de esta tendencia manifiestan la necesidad de fusionar o combinar los imperativos colectivos con las visiones subjetivas y personales, esto último, en medio de complejos debates sobre la eficacia de un "teatro de ideas" y la función de los grupos escénicos como entidades orgánicas o solidarias con el afianzamiento democrático y, a su vez, con el pedido de justicia por los horrores de los distintos terrorismos de Estado regionales. En los relatos del teatrista peruano Miguel Rubio, director general del grupo Yuyachkani, se exponen con claridad estas divergencias subjetivas, estéticas y políticas, dice:

La formación de un grupo era lo que sin ninguna duda correspondía hacer a quienes queríamos cambiar el mundo con el teatro en la década del setenta del siglo pasado [...] Pero, ¿qué es un grupo? Un grupo es un momento determinado de nuestra vida; es necesario saber cuál es ese momento para encontrar oportunamente las preguntas. Creo que la vida en un grupo se fortalece aprendiendo a combinar los espacios colectivos con los personales; en nuestro caso, algunos proyectos involucran a todos y otros son iniciativas particulares que luego de todas maneras repercuten en el colectivo [...] Considero que esta búsqueda ha sido una de las claves para la continuidad en nosotros; pienso que así vamos construyendo una memoria común, matizada por la experiencia de cada uno. (Rubio 2011: s/p).

En este contexto de nuevos posicionamientos intelectuales, donde el "yo" de los creadores se imbrica con los actuales horizontes de expectativa sociales, hallamos a teatristas argentinos que, en la fase de posdictadura, conservan y reproducen algunas estrategias del docudrama para evocar una tesis objetiva sobre lo real/contextual, siendo esta elección estética una de las formas de asumir los mecanismos de representación de la memoria en el teatro.

Un caso paradigmático de esta corriente es la obra El maruchito. Sangre y encubrimiento allí en las tierras del viento de Juan Raúl Rithner, estrenada en el mes de octubre de 1997, en la ciudad de Villa Regina (Provincia de Río Negro, Patagonia Argentina), por el grupo Los Nosotros, con dirección y puesta en escena de Carlos Massolo.

En efecto, este texto dramático puede asociarse con el teatro-documento porque -apelando a registros y huellas historiográficas- busca una contrastación con lo real y sus enunciados tienen el carácter de prueba empírica que ratifica una visión crítica del mundo (Freire 2007: 50).

La estructura textual de la obra está organizada en un extenso acto único, dividido en más de veinte secuencias de acción interdependientes y sin notaciones dramáticas que den cuenta de la división entre unas y otras. Su esquema de ficción plantea una isotopía argumental, esta es, la puesta en escena de un mito popular por parte de una troupe de artistas de circo y radioteatro patagónicos, vale decir, a través del recurso del "teatro dentro del teatro", se aborda la figura 
legendaria del llamado "maruchito": un niño de 10 años, Pedrito Farías, quien -según la tradición oral, leyendas e investigaciones historiográficas- fue asesinado por un trapero a principios de la década de 1920, en los caminos desérticos de la Línea Sur de Río Negro. Luego de este suceso trágico, el niño se convirtió en un símbolo de la región, incluso, con prácticas asociadas a la religiosidad popular.

Desde esta construcción semántica y metaescénica, "el maruchito" fue propuesto por Rithner como una alegoría de las numerosas e injustas "jóvenes muertes" documentadas en diversos momentos históricos, esto es, desde las contiendas anarquistas de principio de siglo XX (con las luchas obreras y la reivindicación de derechos minoritarios), pasando por las distintas dictaduras militares de los años '60 y '70, con la resistencia juvenil como la fuerza matriz del cambio social y la desaparición forzada de personas como su ominosa consecuencia, hasta -finalmente- exponer en esta cadena de significaciones a las "jóvenes muertes" de la Patagonia durante la fase democrática, entendidas como una secuela de la violencia de Estado persistente y ejemplificadas en el emblemático caso del conscripto Omar Carrasco, un antecedente jurídico fundamental para la abolición del servicio militar obligatorio en Argentina y, además, un referente histórico activo para el espectador local en el momento del estreno de la obra.

Así, el texto propone una tesis estructural/objetiva que -fundada en la documentación historiográfica y mítica de la región patagónica- demuestra la vigencia y sistematización de una lógica cultural sobre la tortura, el castigo y hostigamiento del cuerpo/joven como mecanismo de control social y político en distintos períodos. Vale decir, la obra expone -a través de un evidente ejercicio anacrónico de raíz brechtiana- las invariables o constantes históricas sobre la violencia, depositada en los jóvenes como núcleo de las transformaciones y utopías.

En correlato con lo anterior, la estructura ficcional apela a distintos procedimientos dramatológicos de ruptura y transición temporales, tales como elipsis, raccontos y resúmenes (García Barrientos 2012: 103). De este modo, se contrasta la visión anacrónica de los hechos dramatizados con una detallada organización histórico-documental, explicitada además en los paratextos denominados "bibliografía" y "testimonios"3, o también basada en la cita de publicidades de cada momento histórico que son reconocibles por su tradición popular o, incluso, en la intertextualidad con el manifiesto obrero-socialista del $1^{\circ}$ de mayo de 1909 o en la marcha anarquista, entre otras discursividades.

Por lo tanto, el mecanismo de representación de la memoria en esta obra resulta de la documentación historiográfica objetivada en escena y del anacronismo como procedimiento ficcional para elaborar -a partir de la figura alegórica del maruchito- una visión de mundo activa. Así, los procedimientos temporales del texto resignifican su vínculo con la memoria histórica regional, al establecer tensiones entre los tres grados de representación del tiempo (García Barrien-

\footnotetext{
${ }^{3}$ Efectivamente, en la edición de 1998 de El maruchito..., el texto incluye un apéndice denominado "Bibliografía" y "Testimonios", a través del cual el autor da cuenta exhaustiva y detallada de los documentos y fuentes utilizados para la construcción del drama.
} 
tos 2012: 98-99): primero, el grado patente, expuesto en la cadena de sucesos anacrónicos antes indicados, interdependientes entre sí y anclados en distintos momentos del siglo XX; segundo, el grado latente, entendido como el presente histórico del espectador, lo que permite una posible "identificación simpatética" (Jauss 1992: 270) sobre lo escenificado y, desde allí, una aseveración de la tesis social de la obra; tercero, el grado ausente, presentado como un futuro difuso, ambiguo, pero con perspectivas de transformación social, por ejemplo, visible en la didascalia que relata la escena final del espectáculo, cuando los personajes ritualizan la muerte del maruchito. Dicha secuencia dramática propone: "Todos los actores, de pie ahora, miran al público y alzan sus brazos hacia ellos, hacia arriba, hacia un posible y alcanzable horizonte, como quien presenta armas al futuro, armas de la memoria, armas encendidas" (Rithner 1998: 68).

En síntesis, podemos afirmar que en la década de 1990, durante la fase de la "imposición jurídica del olvido"4 (Jelin, 2005), la obra El maruchito... recupera las estrategias poéticas del docudrama propuesto por Weiss en los años '60, mediante la predicación de una tesis estructural sobre la violencia de Estado y su sistematización como una constante lógica cultural.

2. LA VERdAd POÉTICA COMO UN EFECTO DE SENTIDO POLÍTICO EN EL DOCUDRAMA. El caso de la obra El pañuelo de Carlos María Alsina

Al mismo tiempo que el modelo convencional del docudrama se actualiza en los distintos campos artísticos argentinos, encontramos variaciones de su forma con propuestas teatrales y dramatúrgicas de ruptura, en especial, al poner en crisis la visión estructural/objetiva que el modelo original propone.

Entre otros, un caso de estudio para describir esta forma escénica es la obra El pañuelo de Carlos María Alsina. El texto dramático fue escrito y estrenado en 1991 -precisamente- en el marco de las actividades de repudio a la candidatura para gobernador en la Provincia de Tucumán del genocida Antonio Domingo Bussi. La obra se vincula con el docudrama latinoamericano por sus estrategias de composición hipertextual y contratextual, aunque en este caso, los hipotextos utilizados corresponden a poesías, fotografías, cartas, documentos personales y anécdotas de las Madres de Plaza de Mayo, recolectadas por el autor en un singular trabajo de archivo.

El texto dramático es un monólogo breve, con unidad de acción, presentado en un tiempo cronológico, sin cortes o elipsis. El relato se organiza a partir del testimonio de una Madre de Plaza de Mayo que ha decidido "desbordar" el nombre y la fecha de la desaparición de su hijo, tejidos en su alegórico pañuelo blanco. Para dar cuenta de esta acción y sus alcances simbólicos, el autor incorpora -como ya indicamos- figuras poéticas o sucesos recopilados por las Madres durante los años de búsqueda e indolencia social, por ejemplo, la imagen del "pañal hecho pañuelo", o la alusión a sueños ominosos respecto del lugar

\footnotetext{
${ }^{4}$ Nos referimos al período 1986-2003, vale decir, los años del olvido legislativo evidenciado en las leyes de Obediencia Debida, Punto Final e indultos que obturaron todo intento de enjuiciamiento a los genocidas.
} 
donde yacen los cuerpos: "Anoche soñé que me soñabas. Estabas en un mar de aguas lentas, con los muslos atados a las algas" (Alsina, 2006: 158); o también al documentar los originales modos de resistencia política que las Madres generaron para comunicar las desapariciones de sus hijos, nos referimos a la acción de escribir sus denuncias en los billetes de la moneda nación que tenían circulación cotidiana y masiva.

Así, el personaje asume la función de testimoniar -mediante estas imágenes y recuerdos- una operación que, en primera instancia, genera en el lector/ espectador un "efecto de extrañamiento", esto es, en términos brechtianos, que lo familiar se torna extraño, distante; es una acción que rompe con la naturalización de una conducta conocida. Por lo tanto, en la lógica ficcional del relato, desbordar o deshacer el nombre de su hijo desaparecido se convierte en un acto con connotaciones políticas, pero anclado en imágenes y fundamentos subjetivos. Vale decir, implica asumir un posicionamiento ideológico que le permite a una "madre" del dolor convertirse en "Madres", junto con todas las funciones sociales, personales e institucionales que ello involucra. Desde este punto de vista, el personaje dice:

Desbordo tu nombre pensando en el día en que lo elegí cuando todavía habitabas en mi cuerpo [...] Desbordo tu nombre al mismo tiempo que construyo la fortaleza de tu recuerdo, porque no estoy renunciando a vos, hijo querido, ni a la denuncia del abismal día en que te secuestraron, pero sí renuncio definitivamente a tu muerte y a mi exclusividad sobre tu vida, porque es tu vida la que me ha hecho comprender que mi vagina no ha parido un solo hijo, que mis oídos no han sentido un sólo llanto, que no he sido sólo penetrada por la irrepetible sensación de tu presencia. Estoy encinta de sesenta mil ojos, de miles de latidos. Mis entrañas bullen de sexos, de manos, de pupilas. No espero a un sólo hijo. Son miles los que daré a la vida. (Alsina 2006: 159).

En suma, esta particular acción dramática -quizás, al igual que El maruchito..., también con características ritualistas respecto de las muertes ominosas- funda una dialéctica entre lo individual y lo colectivo, entre lo psicológico y lo político-institucional, porque dispone en el orden simbólico el surgimiento de un nuevo habitus, aquí entendido como una articulación de lo subjetivo y lo objetivo, manifestado en esquemas de acción y percepción que los cuerpos han interiorizado (Bourdieu 1988: 133). Puntualmente, nos referimos a la metáfora del "cuerpo-matriz" o "cuerpo-placenta", que albergará a miles de "otros", expresado en la politicidad de las imágenes corporales.

Está dialéctica es puesta en marcha por las fuentes documentales asociadas al texto y por su formato testimonial, esto último, evidenciado en la presencia en acto de un personaje-testigo que ritualiza un "simulacro oral", cuyo pacto ficcional posee voluntad de verdad, como así también reconstruye la lógica del pensamiento de la víctima, con sus recuerdos y sus angustias; además, alcanza unidad dramática en la proyección de los fragmentos de su vida, a los que recurre para denunciar y resignificar los sucesos del pasado. En este sentido, la acción iniciada busca superar un vacío comunicativo, es decir, intenta "poner en diálogo" lo que históricamente se ha silenciado y, a su vez, evitar -lo que Rossana 
Nofal (2002) Ilama- una clausura interpretativa sobre los fenómenos del pasado. Estas características pueden observarse en la tensión que la obra plantea entre la ceremonia de desbordar el pañuelo y la premisa del olvido:

Vos sabés que desbordando tu nombre no te olvido. ¡Cómo voy a olvidar tus pasos, tu crecer, tu aturdimiento de joven, tu timidez incalculable! ¡Cómo voy a olvidar que cada día tenía la mansedumbre serena de tu voz! ¡Cómo olvidarme de tus primeras palabras, y de las últimas! [...] ¡Cómo el olvido puede quemar tus poemas de amor, tus pequeñas ingenuidades y la madurez de saber que era necesario luchar por los demás! (Alsina 2006: 158-159)

De este modo, desbordar el alegórico pañuelo no es olvidar, sin embargo, se expone una tensión entre lo biográfico y la configuración simbólica de lo que ya dijimos en un nuevo cuerpo social e individual a la vez: el pasaje de "madre" a "Madres". Esta operación metonímica implica una resemantización positiva del olvido personal para proyectarse en un acto colectivo.

Por lo tanto, en El pañuelo, la metáfora de un "cuerpo-placenta" que resulta de la acción política descrita, se logra a través de la intertextualidad implícita con fuentes históricas reales y documentos usados como estructura de base para la verosimilitud del relato. Sin embargo, en esta obra las premisas del docudrama logran una variante: los documentos declarados y fundantes de la ficción escénica no son presentados con la objetividad bibliográfica y con la distancia brechtiana que el modelo de Peter Weiss propone y que la obra El maruchito... desarrolla con relativo éxito; por el contrario, en este caso, se amplía o extiende el grado de poíesis ${ }^{5}$ aplicado a los documentos históricos, al intertextualizar los datos y fuentes originales con metáforas, imágenes escénicas y acciones dramáticas no realistas. Este cambio procedimental funda un "pacto ambiguo" con el lector/espectador, quizás, cercano a la definición propuesta por Manuel Alberca (2012) en sus estudios sobre la narrativa. Así, la escena no se convierte en una máquina de traducción de informaciones ocultadas o distorsionadas, con documentos expuestos a dictamen del espectador o al servicio de refutaciones empíricas sobre un pensamiento dominante, sino que se propone una fusión de aspectos subjetivos e imaginarios para articular un "efecto de sentido" sobre el pasado y el presente. Por ende, la escena teatral propone una "verdad poética" que alcanza una relativa autonomía de la "verdad fáctica" extraída de los documentos y fuentes.

\section{El teatro de la "autoficción performáticA" O el CUERPo del actor COMO UN DOCUMENTO HISTÓRICO: EL CASO DE LA OBRA MI VIDA DESPUÉS DE LOLA ARIAS}

Hasta aquí, hemos descrito un proceso estético que, por un lado, se asocia con la forma del docudrama modélico al desarrollar una tesis estructural/objetiva y fundar su teatralidad en un referente histórico, por el otro, hemos reco-

\footnotetext{
${ }^{5}$ Entendiéndolo como espacio estético de productividad ontológico que inaugura toda posible teatralidad (Dubatti 2009).
} 
nocido una variante de la misma corriente en la que se intensifica el tratamiento poético-subjetivo de las fuentes bibliográficas o documentos citados en escena.

Por consiguiente, en esta instancia, resulta pertinente formular los siguientes interrogantes: ¿qué efecto poético se provocaría si la actriz que interpretara el personaje de una Madre de Plaza de Mayo en la obra El pañuelo fuera, en el orden de lo real, una actriz/Madre de Plaza de Mayo? En este hipotético registro del acontecimiento teatral, ¿seguiríamos considerando nuestro análisis desde la perspectiva del docudrama? A su vez, nos preguntamos: ¿qué nuevas dimensiones estéticas se generan cuando es el cuerpo vivo del actor/intérprete el propio documento histórico expuesto en escena y no solo un conjunto de citas bibliográficas, cartas personales, fotografías, estadísticas, etc.? ¿En qué condiciones poéticas y escénicas el cuerpo vivo del actor/intérprete podría ser un documento real y empíricamente verificable del relato ficcionalizado?

A partir de estos ejes problemáticos, podemos describir la tercera forma en la que lo documental, histórico y biográfico, se expone en la escena de la posdictadura argentina como un discurso específico sobre la memoria social. Para lograr este fin, apelaremos a un caso de estudio estratégico: la obra Mi vida después de la directora y dramaturga Lola Arias.

Originalmente pensado como un espectáculo del ciclo Biodrama que -entre los años 2002 y 2008- coordinó la directora teatral Vivi Tellas en la Ciudad Autónoma de Buenos Aires, Mi vida después se estrenó en dicha capital en el año 2009 y, desde entonces, ha generado diversos espacios de crítica y discusión, al mismo tiempo que notorios reconocimientos en los más importantes festivales artísticos y congresos académicos.

En el programa de mano de la obra, se propone una síntesis argumental operativa a nuestros objetivos, dice:

Seis actores nacidos en la década del '70 y principios del '80 reconstruyen la juventud de sus padres a partir de fotos, cartas, cintas, ropa usada, relatos, recuerdos borrados. ¿Quiénes eran mis padres cuando yo nací? ¿Cómo era la Argentina cuando yo no sabía hablar? ¿Cuántas versiones existen sobre lo que pasó cuando yo aún no existía o era tan chico que ni recuerdo? Cada actor hace una remake de escenas del pasado para entender algo del futuro. Como dobles de riesgo de sus padres, los hijos se ponen su ropa y tratan de representar su historia familiar. Mi vida después transita en los bordes entre lo real y la ficción, el encuentro entre dos generaciones, la remake como forma de revivir el pasado y modificar el futuro, el cruce entre la historia del país y la historia privada. (Arias 2009: $s / p)^{6}$

\footnotetext{
${ }^{6}$ Browmell (2009: 6), a su vez, propone otra descripción sobre las líneas argumentales que creemos útil para la comprensión de este espectáculo, dice: "resumamos brevemente la historia que cada actor presenta en la obra: los padres de Liza Casullo (la ya mencionada Ana Amado y el filósofo y escritor Nicolás Casullo) debieron exiliarse en México a causa de su militancia peronista; el padre de Carla Crespo era un dirigente del ERP y, hasta donde se sabe, murió en el enfrentamiento de Monte Chingolo; el padre de Blas Arrese estaba en el seminario estudiando para ser cura; el padre de Mariano Speratti tenía un taller mecánico, era corredor de autos antiguos y militaba en la Juventud Peronista hasta el momento de su desaparición; el padre de Pablo Lugones trabajaba en un banco que fue intervenido, y el padre de Vanina Falco -ella lo supo a los 28 años- era un policía que hacía tareas de inteligencia y fue el apropiador de un bebé nacido en la ESMA (Juan
} 
Dado el dispositivo escénico sobre el que se construye el relato de esta obra, el tratamiento de las fuentes presenta importantes matices y diferencias con los casos anteriores, pues aquí el "documento histórico" no solo se expone como una referencia contratextual o como una huella extraída de un archivo para ser narrada, sino fundamentalmente se "hace carne" y se proyecta en escena a través sus modos conviviales.

Siguiendo los estudios de Pamela Browmell (2009: 5), podemos comprender con mayor precisión este singular procedimiento escénico. Para la citada investigadora, Mi vida después presenta distintos niveles de acción dramática:

a) la biografía del actor como una fuente dramática, básicamente, por el uso testimonial de la primera persona;

b) la remake como un recurso que le permite al actor/hijo interpretar el rol de su propio padre o madre;

c) la representación -a través de formas dramáticas convencionales- de otros roles o personajes presentes en la estructura ficcional;

d) acción performática libre, sin anclaje diegético específico.

Desde nuestro punto de vista, estos cuatro niveles de la acción proponen a su vez tres modalidades en el uso del documento: primero, su exposición "extrañada" con bases en los recursos brechtianos y convencionales del docudrama, permitiendo su típica referencialidad contratextual. Segundo, el documento es "sostenido" por el cuerpo del actor/personaje para promover una reflexión contrastante con el pasado o para indagar en los niveles de subjetividad que aquella huella histórica evoca, entonces, se establece una interdiscursividad entre el cuerpo del performer y el documento histórico, entre lo objetivo/colectivo e histórico y lo subjetivo/individual e imaginativo; por ejemplo, este uso se evidencia en las escenas de comparación fisonómica que se realizan entre el cuerpo del actor/hijo y el de su padre o madre, ya sea, mediante la yuxtaposición visual entre fotografía/pasado y cuerpo/presente o también a través del uso de un vestuario que, originalmente, fue de su progenitor. El tercer uso referencial que proponemos alude al cuerpo vivo del intérprete como un documento directo y sin mediaciones, incontrastable y autorreferencial, esto último, por ser actor/ dramaturgo, performer y personaje al mismo tiempo.

Así, la potencialidad estética que plantea la tercera modalidad descrita, nos permite reflexionar sobre las posibilidades de la escena autoficcional. Desde nuestra perspectiva de análisis, la autoficción en el teatro abriría dos líneas de debate: primero, la vinculada con el "modo" del relato; segundo, las particularidades escénicas del referente abordado, en especial, quién es el "yo" de la autorreferencialidad, entendiéndolo como su punto de inflexión y de distinción con la narrativa y el cine.

\subsection{El "MOdo" de LAS PRÁCticas teatrales autoficcionales}

Para comprender las características autoficcionales en los actuales procesos teatrales, debemos adoptar criterios operativos que nos impidan caer en

Cabandié), su hermano".

100 | Pasavento. Revista de Estudios Hispánicos, vol. III, n. ${ }^{1}$ (invierno 2015), pp. 91-108, ISSN: 2255-4505 
reduccionismos estériles. Por esto, un hipotético teatro autoficcional no será entendido como un género o una forma escénica cerrada, ni perseguiremos una definición esencialista; por el contrario, buscaremos -siguiendo las premisas estéticas de Wittgenstein- determinadas "reglas de juego" y sus correlativos "aires de familia" entre el teatro y las ideas sobre la autoficción vertidas en la novela y el cine. En efecto, para aclarar esta particular postura epistémica, Griselda Barale en sus estudios sobre el filósofo vienés dice:

\begin{abstract}
El arte es un juego del lenguaje más y, como tal, responde a reglas y se legitima en la vida en sociedad, en las formas de vida. Un juego de gran dinamismo y variabilidad en el que intervienen distintas acciones, destrezas, usos, por lo que se lo puede entender como juego de juegos. En efecto, cuando hablamos de "arte" hablamos de "obras de arte" -juegos- en su infinita variedad de estilos, uso de materiales, contextos en los que fueron producidos, géneros, etc. Las obras en su incontable variabilidad no poseen rasgos comunes constantes que nos permitan definirlas y, desde allí, definir al arte. Lo que observamos entre ellas son "aires de familias" y cada una requiere para su conocimiento y disfrute no un procedimiento de reducción esencial sino un conocimiento de detalles y pormenores; un descubrimiento de las reglas de su producción y una interpretación que no será sino el esclarecimiento de las relaciones de las reglas con las formas de vida, con el trasfondo de la cultura que determina los significados por los usos. (Barale 2000: 98)
\end{abstract}

Por consiguiente, para pensar las prácticas escénicas autoficcionales desde la perspectiva de análisis aquí delimitada y, a su vez, localizar sus "aires de familia" con otros juegos del lenguaje teatral contemporáneo, tomaremos como base conceptual las premisas teóricas de Ana Casas, en especial, cuando dice:

... la autoficción lleva al extremo algunos de los recursos empleados en la novela contemporánea y se sitúa en una línea de experimentación que, procedente del Modernismo y las Vanguardias, denuncia la imposibilidad de la representación mimética. La ruptura de la verosimilitud realista se produce, no obstante, estrechando los lazos entre la obra literaria y el universo extratextual: la autoficción llama al referente para negarlo de inmediato; proyecta la imagen de un yo autobiográfico para proceder a su fractura, a su desdoblamiento o a su insustancialización. (Casas 2012: 33-34)

Desde este punto de vista, las escenas del "yo deconstruido" actualizan el debate sobre el modo dramático, es decir, el modo específico de representación mimética de una acción según la tradición aristotélica. En este sentido, los estudios sobre las diferencias de un "teatro dramático" y un "teatro posdramático" nos interesan para inscribir las prácticas autoficcionales en determinadas reglas de juego. En efecto, el primer caso, define un tipo de obra teatral que establece una relación de dependencia con una textualidad preexistente, ya sea por ser su contenido, proyección, anticipo, actualización o, incluso, su negación. Así, los modelos dramáticos creados desde la modernidad hasta la neovanguardia absurdista -esto es, por ejemplo, desde el teatro de Ibsen hasta Beckett- se fundan en su vinculación con lo textual. Por el contrario, a partir de la década de 
1970, se intensifican una serie de prácticas teatrales en las que se promueve una nueva relación entre la escena y los materiales textuales, denominándose a dichas prácticas "teatro posdramático", según los estudios de Hans-Thies Lehmann (2013). En esta modalidad, la tensión que se establece entre el hecho teatral y sus fuentes textuales impugna los principios reguladores de la escena dramática tradicional, de manera general, sostenidos en la mímesis del mundo o de un mundo y su consecuente ilusión de contigüidad o figuración metonímica. Por lo tanto, independientemente de las complejas y múltiples tendencias desplegadas en el teatro posdramático actual, destacamos aquí la no preexistencia de un referente para la construcción de su dispositivo escénico7; vale decir, en este "modo", la escena se piensa a sí misma, elabora sus propias formas y dimensiones en un tiempo presente y fugaz, sin remitir a otras realidades que la de los cuerpos sin mediaciones, inscriptos en una particular dinámica entre espacios, imágenes, sonidos y acciones, entre otros numerosos recursos.

La búsqueda de una realidad no preexistente como fuente escénica conlleva a trabajar con lo "inmediato": el cuerpo/memoria del actor. En consecuencia, en estas singulares coordenadas estéticas emergen las distintas variantes de una posible práctica teatral autoficcional, pues, la escena autorreferencial deviene -en algunos casos, como en el ya citado ejemplo de Mi vida después-en autoperformática.

Es precisamente esta condición de inmediatez del modo dramático lo que ha generado el comentario de distintos especialistas respecto de las "(im) posibilidades" de, por ejemplo, un drama autobiográfico, tal como lo analiza José Luis García Barrientos (2009). En efecto, el investigador mencionado debate sobre las características del relato factual, homodiegético y con contenidos autorreferenciales que un teatro autobiográfico debería cumplir, pues, para él, el drama no accedería a un relato en primera persona, ni podría generarse una dimensión escénica "sin mácula de ficción" (95), es decir, puramente factual; por lo tanto, solo se verificaría la igualdad entre autor y personaje, esto último, sin la mediación de un narrador (o modo "mediato"), el cual sería inexistente en la forma dramática, dada su inmediatez (o modo "no mediato"). A su vez, García Barrientos confronta estas conclusiones teóricas con dos casos de estudio que le permiten corroborar cierta condición de posibilidad para esta forma escénica, la cual radica en objetivar dramáticamente lo subjetivo o, lo que es lo mismo, hacer inmediato lo mediado por el yo del autor (101).

Si bien coincidimos con esta regla del juego teatral planteada por García Barrientos, creemos que las modalidades escénicas posdramáticas han encontrado un modo específico de inscribir determinados aspectos factuales y homodiegéticos en la inmediatez de la escena, en especial, han logrado dramatizar relatos autobiográficos a través de la deconstrucción del yo del actor. Así, el modo "no mediato" del actor le permite apelar a datos autobiográficos para fracturar

\footnotetext{
7 Si bien conocemos los diversos formatos de la escena posdramática descritos por Hans-Thies Lehman, en este caso puntual, sólo aludimos a aquellos modos creativos en los que hallamos la no preexistencia de un referente, por lo tanto, no incluimos a los fenómenos teatrales posdramáticos que -por ejemplo- parten de la actualización de un texto clásico.
} 
dichos referentes en pleno proceso escénico, siendo este artilugio deconstructivo una forma singular de la inmediatez contemporánea.

Asimismo, la valoración del modo inmediato propio del "teatro dramático" se actualiza y profundiza de manera exhaustiva en el "teatro posdramático" como una función política, pues la conciencia biográfica, corporal, espacial y temporal del actor como principios constructivos de la fugacidad escénica lo convierten en el referente principal del relato -o también llamada "autopoiesis del actor", tal como lo define Erika Fischer-Lichte (2011: 325)-, siendo las prácticas autoficcionales - particularmente las del teatro de la posdictadura argentina que hemos analizado- una de sus diversas variantes modales. Esta condición política de la inmediatez posdramática podría, por sus aires de familia, entenderse como una posible función estética del teatro autoficcional. Al respecto, Óscar Cornago señala:

Político, en su sentido más amplio, va a dejar de ser una ideología determinada, para ser en primer lugar una manera de estar -en la escena de la historia- que parte de una fuerte conciencia de presente, de proximidad con un aquí y un ahora inevitablemente escénicos; político es el momento en que un actor, que no tiene otro nombre más que el suyo propio, sale al escenario y se dirige al público, un tipo de comunicación que se lleva a su máximo grado de realidad; político es, en definitiva, este contexto de comunicación inmediato y concreto, levantado desde un cuerpo físico y real, más histórico cuanto más natural, que siente y piensa de una manera determinada, que va a ser confrontado con ese otro al que se dirige, que es el público; política es la comunicación con el otro. (Cornago 2013: 135)

Precisamente, esta singular forma de inmediatez escénico-actoral y política implicaría una de las posibles reglas de juego autoficcionales en el teatro ${ }^{8}$.

\subsection{De LA REFERENCIALIDAD HISTÓRICA A LA AUTORREFERENCIALIDAD}

La predisposición escénica del cuerpo/real del actor como matriz para la creación posdramática -así como para su variante autoficcional-conlleva a establecer una diferencia central: en el docudrama el referente sintagmático proviene de la "historia", en cambio, en la autoficción escénica dicho referente es la "memoria" del dramaturgo/performer. Esta distinción nos permitirá avanzar en otra posible regla de juego de la modalidad teatral aquí tratada.

En función de los tres casos de estudio descritos y sus correlativas formas poéticas, podemos analizar estas lógicas referenciales.

En primer término, el referente histórico en el docudrama modélico admite una prueba empírica por aludir a situaciones, personajes u objetos conocidos por el espectador. Así, su teatralidad se funda en un "hecho sucedido" que deviene en un "hecho escénico", pero dramatizado a través de "fisuras" en

\footnotetext{
${ }^{8}$ El estudio de Beatriz Trastoy (2002) sobre las fuentes autobiográficas y el relato de vida en los unipersonales del teatro argentino de las décadas de 1980 y 1990 también ratifica esta impronta modal y política.
} 
lo supuestamente conocido y aceptado por el saber colectivo o por los discursos hegemónicos. Vale decir, se promueve una resemantización de los hechos, con el fin de inducir a un proceso crítico/materialista sobre aquellos fenómenos comunitarios. De este modo, el discurso ficcional-teatral se convierte en un mecanismo de confrontación con "la verdad", esto último, mediante un procedimiento de contratextualización que le permitirá al espectador contrastar entre lo conocido/aceptado históricamente y lo resignificado en el orden escénico (Freire 2007: 86-95).

Por el contrario, en la lógica referencial del teatro autoficcional, el vínculo contextual no se establece solo por aludir a marcos preexistentes y reconocidos por el público, sino también por conformar una cadena "compleja"9 (Morin 1994) de significantes, por los cuales se genera un "simulacro referencial" ambiguo, contradictorio y azaroso. Por ejemplo, en el caso de la obra Mi vida después, esta ilusión referencial se evidencia en los anclajes y coordenadas sobre la dictadura militar narrados en el espectáculo; no obstante, dicha referencia no se crea a partir de un sintagma historiográfico, sino a través de la ya mencionada inmediatez escénico-política del actor, quien escenifica un singular "trabajo de la memoria" con fuentes autopoiéticas. Por "trabajo de la memoria", entendemos -siguiendo los estudios de Elizabeth Jelin (2002) - a las prácticas intersubjetivas forjadas a partir de las experiencias simbólicas y materiales del pasado, esto último, en plena tensión con lo autobiográfico y con un hipotético "yo plural". Esta productividad del "presente del pasado" (19) requiere, por un lado, un proceso social de escucha creativa y comprometida, por otro, una innovación semántica de las estructuras significativas evocadas y no solo su mera repetición o reproducción, siendo la praxis escénica uno de sus múltiples "vehículos de la memoria" (37) y, a su vez, estos procesos convierten al dramaturgo/performer de la escena autoficcional en un "emprendedor de la memoria" (86). En suma, esta lógica promueve un simulacro referencial del yo del actor, elaborado mediante una cadena de significantes autobiográficos y asociativos, pero, al mismo tiempo, estas secuencias yoicas son deconstruidas por la yuxtaposición y contraste con el "yo plural" del resto de los actuantes en el convivio teatral y por la "identificación irónica" (Jauss 1992: 283) que el relato suscita.

Esta deriva referencial se sostiene -a diferencia del componente historiográfico y objetivo del docudrama tradicional- en un mecanismo ominoso y fantasmagórico. De este modo, podríamos preguntarnos: ¿qué huellas mnémicas evoca el actor en la escena autoficcional? Si bien existen conocidos estudios actorales sobre la memoria en el actor, recordemos los trabajos de la memoria emotiva o la memoria sensorial de Constantin Stanislavski ${ }^{10}$, en este caso - por las dimensiones estéticas y políticas ya indicadas- podemos hallar ciertos aires

9 Recordemos que para Edgar Morin (1994) el "pensamiento complejo" remite a diversas operaciones, tales como religar y asumir las contradicciones y el desorden inmanentes; trabajar desde la incerteza, lo que no significa dejarse sumergir en ella; incorporar lo imprevisible; abolir la disyunción y la reducción mutilantes; en suma, abordar los principios de la distinción, la conjunción y la implicación como bases de la complejidad.

10 Véase Stanislavski (1980; 1986).

104 | Pasavento. Revista de Estudios Hispánicos, vol. III, n. ${ }^{1} 1$ (invierno 2015), pp. 91-108, ISSN: 2255-4505 
de familia con la "lógica del fantasma" definida por el psicoanálisis lacaniano. Desde esta perspectiva teórica, el fantasma es una estructura significante producto de la carencia de un objeto imaginario y que, paralelamente, le permite al sujeto sostener su deseo o, en otros términos, es la respuesta simbólica al deseo enigmático del Otro, quizás, traducido en el interrogante: ¿qué quiere el Otro de mí? (Evans 2007: 90-91). En efecto, como ha demostrado Wagner-Egelhaaf (2012), el fantasma es una figura constante en las prácticas literarias autoficcionales, y su productividad se expresa en la vacilación de los límites entre la ficción narrativa homodiegética y la escritura autobiográfica factual (257-258).

Por consiguiente, el relato autoficcional de la obra Mi vida después se genera por la deconstrucción de cierta lógica del fantasma, al tensionar o poner al límite los artilugios posdramáticos y las fuentes biográficas de los actores, aquí manifestadas en las configuraciones imaginarias paternas y maternas respecto de la dictadura militar. Vale decir, si en la estructura dramática de Hamlet de Shakespeare, la potencia actancial del personaje responde al interrogante: ¿qué quiere de mí la sombra de mi padre?, inscribiéndose así en la lógica del fantasma, entonces, los personajes de la obra de Lola Arias pueden leerse como múltiples proyecciones hamletianas, en tanto, la fuerza del relato autoficcional escenificada también se anida en dicho interrogante ominoso, aunque en este caso, reiteramos, la referencialidad a los fantasmas familiares es deconstruida por una serie de procedimientos dramatúrgicos.

En la obra Mi vida después, la condición convivial del cuerpo/documento del performer no implica solo una construcción metafórica, como hemos expuesto en el caso de la obra El pañuelo; por el contrario, aquí la lógica del fantasma y el cuerpo vivo e inmediato del intérprete es el referente convocado y, a partir de esta condición estética, se conjura una ficción yoica. Ahora bien, tal como señalamos a partir de las premisas conceptuales de Ana Casas (2012: 34), en este ejercicio autobiográfico del performer en escena, el yo es impugnado, desdoblado, desmantelado e, incluso, negado por diversos procedimientos dramatúrgicos y escénicos que muestran un singular mecanismo de representación de la memoria en el teatro argentino actual. Entre otros, podemos mencionar los siguientes recursos:

a) el montaje o collage de fragmentos autobiográficos disímiles e incompatibles, por ejemplo, al poner en escena a un hijo de desaparecidos junto con una hija de militares apropiadores de niños;

b) las digresiones subjetivas y/o fantásticas resultantes del análisis de los documentos citados en escena, declaradas por medio de los recursos metateatrales;

c) las ambigüedades e incertezas del yo, expuestas a través de las contradicciones identitarias o de las confrontaciones con los fantasmas paternos y maternos, ya sean militantes desaparecidos, exiliados, civiles cómplices o apropiadores de niños;

d) el azar y la fuerza heurística de lo imaginario como procedimientos que irrumpen irónicamente en la presentación de los recuerdos infantiles o de los ideologemas históricos, tanto del pasado, como del presente y del 
futuro. Por ejemplo, estas características se observan en la escena de una tortuga que es incorporada al juego escénico con la facultad -siempre contingente- para decidir si habrá o no una "revolución política" en la Argentina del futuro.

En este punto del análisis, las reglas del juego sobre el "modo" posdramático y los mecanismos referenciales se interrelacionan entre sí, pues, debemos preguntarnos: ¿quién escribe en el teatro contemporáneo? Responder a este interrogante no es aludir al clásico dramaturgo de gabinete. Hoy, la respuesta a esta cuestión implica asumir la existencia de un sujeto creador múltiple, compuesto por diversas voces, la de los actuantes y la de los operantes del acontecimiento escénico. En este sentido, es pertinente recuperar la noción de dramaturgia propuesta por el director e investigador teatral Eugenio Barba (1997: 77), para quien dicha actividad no remite a la escritura de un texto, sino a un "trabajo escénico de la acción", esto último, según la etimología de la palabra dramaturgia: drama/acción y érgon/trabajo. De este modo, hoy el dramaturgo es un creador colectivo, un tejedor de acciones en escena, independientemente del sujeto responsable de escribir u organizar la notación dramática final para el registro legal o comercial del texto.

Por consiguiente, a partir de esta lógica modal y referencial, podemos inferir que la relación de equivalencia en un hipotético teatro autoficcional podría ser: actor/dramaturgo = performer = personaje, estableciéndose una variante que podríamos Ilamar "autoficción performática", quizás, la única modalidad posible de reconocer en el arte teatral.

En síntesis, en Mi vida después y en las prácticas escénicas autoficcionales que tienen "aires de familia" con esta tendencia estética, hallamos un modo particular de conjurar el olvido y un específico acontecimiento teatral para "tramitar" el dolor histórico e individual, esto último, sin dogmatismos o tesis estructurales; por el contrario, se configura un giro subjetivo frente a lo objetivo/ verdadero, con la intención de asumir un "pensamiento complejo" (Morin 1994) en la construcción escénica de la memoria histórica.

\section{OBRAS CITADAS}

Alberca, Manuel (2012): "Novelas del yo". En: Ana Casas (ed.): La autoficción. Reflexiones teóricas. Madrid, Arco Libros, pp. 123-149.

Alsina, Carlos María (2006): "El pañuelo". En: Hacia un teatro esencial. Buenos Aires, Inteatro, pp. 155-159.

Arias, Lola (2009): Mi vida después. Buenos Aires, Programa de mano del espectáculo.

Barale, Griselda (2000): "Los juegos del lenguaje en la reflexión estética". En: Roberto Rojo (dir.): Wittgenstein. Los hechizos del lenguaje. S. M. de Tucumán, Facultad de Filosofía y Letras, Universidad Nacional de Tucumán, pp. 75-110.

Barba, Eugenio (1997): Anatomía del actor. México, Escenología/La Gaceta.

Bourdieu, Pierre (1988): "Espacio social y poder simbólico". En: Cosas dichas. Buenos Aires, Gedisa, pp. 128-153. 
Brownell, Pamela (2009): "El teatro antes del futuro: sobre Mi vida después de Lola Arias", Revista Telondefondo, n 10, pp. 1-13.

Casas, Ana (2012): "El simulacro del yo. La autoficción en la narrativa actual". En: Ana Casas (ed.): La autoficción. Reflexiones teóricas. Madrid, Arco Libros, pp. 9-42.

Cornago, Óscar (2013): "La escena en tiempo presente: teatro y performance desde los años noventa". En: Cipriano Argüello Pitt (ed.): Ensayos. Teoría y práctica del acontecimiento escénico. Córdoba, Alción y DocumentA/Escénicas, pp. 131-144.

Dubatti, Jorge (2009): Introducción al teatro comparado. Buenos Aires, Atuel.

Evans, Dylan (2007): Diccionario introductorio de psicoanálisis lacaniano. Buenos Aires, Paidós.

Fischer-Lichte, Erika (2011): Estética de lo performativo. Madrid, Abada.

Freire, Silka (2007): Teatro documental latinoamericano. La Plata, Editorial Al Margen.

García Barrientos, José Luis (2009): "(Im)posibilidades del drama autobiográficos...". En:

Osvaldo Pellettieri (dir.): En torno a la convención y la novedad. Buenos Aires, Galerna, pp. 93-104.

- (2012): Cómo se comenta una obra de teatro. México DF, Editorial Paso de Gato.

Jelin, Elizabeth (2002): El trabajo de la memoria. Buenos Aires, Siglo xxı.

— (2005): "Los derechos humanos entre el Estado y la sociedad". En: Juan Suriano

(dir.): Nueva historia argentina. Dictadura y democracia (1976-2001). Buenos Aires,

Sudamericana, pp. 509-557.

Jauss, Hans Robert (1992): Experiencia estética y hermenéutica literaria. Madrid, Taurus.

Lehmann, Hans-Thies (2013): Teatro posdramático. Murcia, Cendeac/Ad Litteram.

Morin, Edgar (1994): Introducción al pensamiento complejo. Barcelona, Gedisa.

Nofal, Rossana (2002): La escritura testimonial en América Latina. San Miguel de Tucumán, Instituto Interdisciplinario de Estudios Latinoamericanos, Universidad Nacional de Tucumán.

Rithner, Juan Raúl (1998): El maruchito. Sangre y encubrimiento allí en las tierras del viento. Buenos Aires, Ediciones Último Reino.

Rubio, Miguel (2011): "Yuyachkani, 40 años de teatro". En: Sin título. Técnica mixta. Santiago de Chile, Programa de mano del espectáculo, Festival de Teatro Internacional Santiago a Mil, pp. 3-6.

Safouan, Moustapha (2003): Lacaniana II. Los seminarios de Jacques Lacan 1964-1979. Buenos Aires, Paidós.

Sarlo, Beatriz (2005): Tiempo pasado. Cultura de la memoria y giro subjetivo. Una discusión. Buenos Aires, Siglo xxI.

Stanislavski, Constantine (1980): El trabajo del actor sobre su papel. Buenos Aires, Quetzal.

- (1986): El trabajo del actor sobre sí mismo. Buenos Aires, Quetzal.

Tossi, Mauricio (2012): "El vínculo mujer/testimonio en la dramaturgia del noroeste argentino", Revista Telondefondo, n. ${ }^{\circ} 15$, pp. 59-76.

Trastoy, Beatriz (2002): Teatro autobiográfico. Los unipersonales de los 80 y 90 en la escena argentina. Buenos Aires, Nueva Generación.

Wagner-Egelhaaf, Martina (2012): "La autoficción y el fantasma". En: Ana Casas (ed.): La autoficción. Reflexiones teóricas. Madrid, Arco Libros, pp. 237-258. 
Mauricio Tossi

Weiss, Peter (1976): "Notas sobre el teatro documental". En: Escritos políticos. Barcelona, Lumen, pp. 97-111.

108 Pasavento. Revista de Estudios Hispánicos, vol. III, n. 1 (invierno 2015), pp. 91-108, ISSN: 2255-4505 